\title{
Supplementation With Three Different Macular Carotenoid Formulations in Patients With Early Age-Related Macular Degeneration.
}

\author{
James Loughman \\ Technological University Dublin, james.loughman@tudublin.ie \\ Sarah Sabour-Pickett \\ Technological University Dublin, sarah.sabour-pickett@tudublin.ie \\ Stephen Beatty \\ Technological University Dublin
}

See next page for additional authors

Follow this and additional works at: https://arrow.tudublin.ie/otpomart

\section{Recommended Citation}

Loughman, J. et al. Supplementation with three different macular carotenoid formulations in patients with early age-related macular degeneration. Retina, the journal of retinal and vitreous diseases 34(9) Pg.

1757-1766, 2014. doi :10.21427/wt1t-n414

This Article is brought to you for free and open access by ARROW@TU Dublin. It has been accepted for inclusion in Articles by an authorized administrator of ARROW@TU

Dublin. For more information, please contact arrow.admin@tudublin.ie, aisling.coyne@tudublin.ie, gerard.connolly@tudublin.ie.

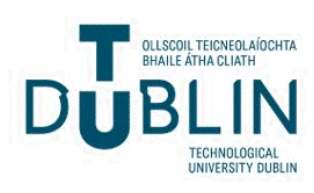




\section{Authors}

James Loughman, Sarah Sabour-Pickett, Stephen Beatty, Eithne Connolly, Jim Stack, Alan Howard, Ronald Klein, Barbara Klein, Stacy Meuer, Chelsea Myers, Kwadwo Akuffo, and John Nolan 


\title{
SUPPLEMENTATION WITH THREE DIFFERENT MACULAR CAROTENOID FORMULATIONS IN PATIENTS WITH EARLY AGE-RELATED MACULAR DEGENERATION
}

\author{
SARAH SABOUR-PICKETT, PHD, $* \dagger+$ STEPHEN BEATTY, MD, FRCOPHTH, $\dagger+$ \\ EITHNE CONNOLLY, BSc, $\dagger+$ JAMES LOUGHMAN, PhD, $* \S$ JIM STACK, PhD, $\dagger$ ALAN HOWARD, PhD, , \\ RONALD KLEIN, MD, MPH,** BARBARA E. KLEIN, MD, MPH,** STACY M. MEUER, BSC,** \\ CHELSEA E. MYERS, MSTAT, $* *$ KWADWO O. AKUFFO, OD $\uparrow$ JOHN M. NOLAN, PHD $\dagger+$
}

\begin{abstract}
Purpose: To investigate the impact of three different macular carotenoid formulations on macular pigment optical density and visual performance in subjects with early age-related macular degeneration.

Methods: Fifty-two subjects were supplemented and followed for 12 months, 17 of them were in intervention Group 1 (20 mg/day lutein and $2 \mathrm{mg} /$ day zeaxanthin); 21 in Group 2 (10 mg/day meso-zeaxanthin, $10 \mathrm{mg} /$ day lutein, and $2 \mathrm{mg} /$ day zeaxanthin); and 14 in Group 3 (17 mg/day meso-zeaxanthin, $3 \mathrm{mg} /$ day lutein, and $2 \mathrm{mg} /$ day zeaxanthin). The macular pigment optical density was measured using customized heterochromatic flicker photometry, and visual function was assessed using corrected distance visual acuity and by letter contrast sensitivity.
\end{abstract}

Results: A statistically significant increase in the macular pigment optical density was observed at all measured eccentricities in Group $2(P \leq 0.005)$ and in Group $3(P<0.05$, for all), but only at $1.75^{\circ}$ in Group $1(P=0.018)$. Statistically significant $(P<0.05)$ improvements in letter contrast sensitivity were seen at all spatial frequencies (except 1.2 cycles per degree) in Group 3, and at low spatial frequencies in Groups 1 and 2.

Conclusion: Augmentation of the macular pigment optical density across its spatial profile and enhancements in contrast sensitivity were best achieved after supplementation with a formulation containing high doses of meso-zeaxanthin in combination with lutein and zeaxanthin.

RETINA 0:1-10, 2014

$\mathrm{T}$ he prevalence of age-related macular degeneration (AMD), the leading cause of blind registration in the developed world, ${ }^{1}$ is rising because of increasing longevity. ${ }^{2,3}$ Although antivascular endothelial growth factor therapy has resulted in better outcomes for patients with neovascular AMD, ${ }^{4}$ this treatment is expensive and cumbersome to the patient and to the health care provider.

Investigators interested in exploring ways of preventing, delaying the onset, or retarding the progression of AMD have directed their attention toward the possible protective role of macular pigment (MP), a yellow-colored pigment that accumulates within the inner retinal layers at the macula ${ }^{5}$ and is optically undetectable beyond $7^{\circ}$ eccentricity. ${ }^{6}$ Macular pigment is composed of three carotenoids, lutein (L), zeaxanthin (Z), and meso-zeaxanthin (MZ) ${ }^{7,8}$ Macular pigment has generated interest in recent years because of its possible protective role for AMD, putatively attributable to its antioxidant properties and/or its prereceptoral filtration of damaging (short-wavelength) blue light, given that (photo-) oxidative retinal injury is known to be important in the pathogenesis of this condition. ${ }^{9,10}$

Low levels of MP are associated with known risk factors for AMD, namely, increasing age, a positive family history of the condition, tobacco use and obesity, before the onset of disease. ${ }^{11}$ Furthermore, 
observational studies have shown that low levels of carotenoids in the $\operatorname{diet}^{12-16}$ and in the serum ${ }^{13,17-19}$ are associated with the risk of AMD. Importantly, MP augmentation has repeatedly been demonstrated after dietary modification and/or supplementation with its constituent carotenoids, in subjects with and without AMD. ${ }^{20-26}$

Although $\mathrm{L}$ and $\mathrm{Z}$ concentrations in a variety of foodstuffs have been determined, ${ }^{27,28}$ the $\mathrm{MZ}$ composition of foodstuffs typical of a western diet has not been investigated satisfactorily, ${ }^{28}$ although it has been identified in certain types of seafood. ${ }^{29}$ Interestingly, MZ has been found, albeit in trace amounts, in the serum of subjects who have not been supplemented with this carotenoid. ${ }^{30}$

There is consensus that MP plays an important role in visual performance. Many cross-sectional studies have shown a positive association between MP and measures of visual performance, including visual acuity, contrast sensitivity (CS), photostress recovery and glare disability (among others). ${ }^{31-35}$ It has also been shown that supplementation with the macular carotenoids improves parameters of visual function in patients afflicted with the early form of this condition. ${ }^{36-38}$ However, no study has yet investigated the impact of a formulation containing MZ on visual function in subjects with early AMD, or on the natural course of this condition.

Certain properties of $\mathrm{MZ}$ render this carotenoid of particular interest when investigating AMD prevention, or when studying the contribution that MP makes to visual performance and experience (in subjects with or without AMD), and these include: MZ is believed to be generated from $\mathrm{L}$ in the primate retina ${ }^{39}$; MZ is the dominant carotenoid at the epicenter of the

From the *Department of Optometry, School of Physics, Dublin Institute of Technology, Dublin, Ireland; †Macular Pigment Research Group, Waterford Institute of Technology, Waterford, Ire-

AU1 land; $\ddagger$ Institute of Eye Surgery and Institute of Vision Research, Whitfield Clinic, Waterford, Ireland; §African Vision Research Institute, Faculty of Health Sciences, University of KwaZulu-Natal, Durban, South Africa; IHoward Foundation, Cambridge, United Kingdom; and **Department of Ophthalmology and Visual Sciences, University of Wisconsin, Madison, Wisconsin.

This study was conducted at the Institute of Vision Research and Institute of Eye Surgery, Whitfield Clinic, Waterford, Ireland.

Supported by a grant from The Howard Foundation, Cambridge CB22 5LA, United Kingdom. The principal investigator (J.M.N.) is currently funded by the European Research Council.

J. Loughman, J. M. Nolan, and S. Beatty do consultancy work for Nutraceutical companies in a personal capacity. J. M. Nolan and S. Beatty are directors of Nutrasight Consultancy Limited. A. Howard is a Chairman of the Howard Foundation, a foundation that supports research in the field of nutrition and health. The other authors have no AU3 conflicting interests to disclose.

AU2 Reprint requests: John M. Nolan, PhD, Macular Pigment Research Group, Carriganore House, WIT, West Campus, Waterford, Ireland; e-mail: jmnolan@wit.ie macula ${ }^{40}$; MZ seems to be the most powerful antioxidant of the macular carotenoids in the presence of the xanthophyll-binding proteins ${ }^{41}$; the presence of all three macular carotenoids is required if MP is to maximally exert its antioxidant effects ${ }^{42}$; the presence of MZ facilitates a wider range of pre-receptoral blue light filtration by MP. ${ }^{43,44}$ Interestingly, an atypical central dip in the spatial profile of MP, characterized by the lack of a central peak with a monotonic decline from the foveal center, is associated with risk for AMD. ${ }^{45}$ It is reasonable to hypothesize that such atypical profiles may be attributable, at least in part, to a lack of MZ, and a consequential lack of MP at the site of dominance of this carotenoid (i.e., at the foveal center). Interestingly, supplementation with a formulation containing MZ has the ability, uniquely, to rebuild MP centrally and confer a typical central peak to its spatial profile. $^{30,46}$

This single-blind, randomized control trial was designed to compare the effect of three differing macular carotenoid formulations on MP enhancement, on visual performance, and on disease progression in subjects with early AMD.

\section{Methods}

\section{Subjects and Study Design}

This study was conducted at the Institute of Vision Research and Institute of Eye Surgery, Waterford, Ireland. The inclusion criteria were: early AMD (the presence of drusen and pigmentary changes) in at least 1 eye; corrected distance visual acuity of $\geq 6 / 12$ in the study eye. The exclusion criteria were: a recent history (within 3 months of baseline visit) of macular carotenoid supplementation; diabetes mellitus; any visually consequential ocular comorbidity. Ethics approval was granted by the Waterford Regional Hospital Ethics Committee, and written informed consent was secured from each subject. The research was conducted in accordance with the principles of the Declaration of Helsinki.

The Meso-zeaxanthin Ocular Supplementation Trial: Report 1 (trial registration number: ISRCTN60816411) is a randomized single-blind clinical trial of oral supplementation with 1 of 3 different interventions. Subjects were randomly assigned to one of three supplementation groups, as follows: Group 1: $20 \mathrm{mg} \mathrm{L}$ and $2 \mathrm{mg} \mathrm{Z}$ (Ultra Lutein); Group 2: $10 \mathrm{mg} \mathrm{MZ,} \mathrm{AU4}$ $10 \mathrm{mg} \mathrm{L}$, and $2 \mathrm{mg} \mathrm{Z}$ (Macushield); Group 3: $17 \mathrm{mg} \mathrm{MZ}, 3 \mathrm{mg} \mathrm{L}$, and $2 \mathrm{mg} \mathrm{Z}$ (prepared especially for this trial by Industrial Organica, Monterrey, Mexico). Subjects were required to consume one tablet daily with a meal. Study visits were carried out at baseline and at 12 months. A demographic, medical, 
ophthalmic, and lifestyle case history was obtained for each patient at baseline.

\section{Macular Pigment Optical Density}

Each subject's MP spatial profile was obtained with the Macular Densitometer, using a methodology that has been slightly modified from that developed by Wooten et al. ${ }^{47} \mathrm{~A}$ detailed description of this protocol has been previously described. ${ }^{48,49}$

\section{Visual Performance}

Corrected distance visual acuity was measured for the study eye monocularly using the Early Treatment Diabetic Retinopathy Study logMAR chart (Test Chart 2000 PRO; Thomson Software Solutions, Hertfordshire, England, United Kingdom), with the room lights on. Contrast sensitivity was also assessed using the $\log$ MAR chart at 5 different spatial frequencies (1.2, $2.4,6.0,9.6$, and 15.15 cycles per degree). For a given spatial frequency, subjects were asked to read out the letters while fixating on the chart at a distance of $6 \mathrm{~m}$. The letter set was randomized during the test at each change of contrast. The percentage contrast of letter optotypes was reduced in $0.15 \log C S$ steps until the lowest contrast value at which subjects see at least 3 letters was reached. The test is then repeated for the other spatial frequencies. Each letter has a nominal $\log C S$ value of 0.03 . Missed letters at any contrast level are noted. The resultant $\log C S$ value for the subject at a particular spatial frequency is calculated by adding any extra letter(s) and/or subtracting missed letters from best $\log C S$ value corresponding to the lowest percentage contrast.

\section{Morphologic Assessment}

Subjects recruited into the study had early AMD. To establish AMD status, color stereoscopic $30^{\circ}$ fundus photographs were obtained using a Zeiss VisuCam (Carl Zeiss Meditec AG, Jena, Germany) and were graded at the Ocular Epidemiology Reading Center at the University of Wisconsin, Madison, WI, using a modified version of the Wisconsin Age-Related Maculopathy Grading System and based on the 11-step AREDS grading scale. ${ }^{50,51}$ For the purposes of this study, a change of two or more steps along the AREDS severity scale was defined as being clinically meaningful. $^{52}$

\section{Clinical Pathology Analysis}

Clinical pathology analysis was performed by Biomnis Laboratories (Dublin, Ireland) to test for changes in renal and liver function, lipid profile, hematologic profile, and inflammation markers at baseline and after the 12-month supplementation period. A detailed description of the protocol has been previously described by our group. ${ }^{53}$

\section{Statistical Analysis}

Statistical analysis was performed using the software package PASW Statistics 18.0 (IBM Corp, Somers, NY). Power and sample size calculations were obtained using PASS 2008 (NCSS, LLC, Kaysville, UT). A priori statistical methodology was not used in this exploratory study.

Baseline differences between intervention groups were assessed using analysis of variance and contingency table analysis, as appropriate. Baseline and 12-month visit measures, within each treatment group, were compared using the paired-samples $t$-test; between-group comparisons, using analysis of variance, would have lacked statistical power because of the relatively small sample size in this study. The change in AMD-severity grade between the three intervention groups was assessed using the Pearson chi-square test for contingency tables. The 5\% level of significance was used throughout.

For the paired $t$-test analyses of changes in MP optical density (MPOD) and CS (reported in Tables 3 and 4), power calculations were based on a "large" effect size of 0.8 standard deviations (as suggested by Cohen ${ }^{54}$ ), and on the smallest of the group sizes (Group $3, \mathrm{n}=14)$; this study was not powered to detect smaller effect sizes, as per Cohen's definitions. ${ }^{54}$ With the usual assumptions (5\% level of significance, 2-tailed test), the power is 0.79 for the Group 3 investigations and higher than this for the other two groups. For the contingency table analysis designed to detect changes on the AMDseverity scale (reported in Table 5), we also used a "large" effect size ( $\mathrm{W}=0.5$ using Cohen's classification) and, in addition, combined some adjacent columns; in this case, the power is 0.78 .

\section{Results}

\section{Baseline Analysis}

Sixty-seven eyes (of 67 subjects) were recruited into this study. Eight subjects discontinued for personal reasons, 3 were not available to attend for the 12month visit, 2 discontinued for health reasons (deemed to be unrelated to intervention), 1 had cataract surgery on the study eye before the 12-month visit, and 1 patient developed neovascular AMD and did not reattend, leaving 52 subjects with complete data sets for the 12-month analyses: 17 in Group 1, 21 in Group 2, and 14 in Group 3. Baseline demographic, lifestyle, 
anthropometric, and visual data for the remaining 52

T1 subjects are presented in Table 1. Of note, there was

AU5 no significant difference between the groups in any baseline data variables (including AMD severity, data not presented).

\section{Longitudinal Analysis}

Values for MPOD at each eccentricity, at baseline,

T2 and 12 months are summarized in Table 2.

Letter CS at baseline and 12 months, for each of the

T3 5 spatial frequencies, is summarized in Table 3. Graphical representations of letter CS at baseline and at 12 months, for the 3 intervention groups, and for F1 each spatial frequency, are displayed in Figure 1, A-C.

The proportion of subjects in each intervention group exhibiting a change in severity scale grade of two or more, considered clinically meaningful for the purpose of this study, ${ }^{52}$ was studied. Seventy-nine percent of subjects exhibited no clinically meaningful change in AMD severity grade between baseline and 12 months, with $11 \%$ exhibiting deterioration and $10 \%$ exhibiting an improvement. There was no statistically significant difference between treatment groups in change in the AMD severity scale $(P=0.455$, Pearson chi-square test). The 24- and 36-month data will further inform this important analysis.

Clinical pathology analysis results are reported in Table 4. Of note, 2 variables in Group 1, 2 variables in Group 2, and 2 variables in Group 3 demonstrated statistically significant changes from baseline (in both positive and negative directions). All variables, however, remained within their respective and normal reference ranges.

\section{Discussion}

The Meso-zeaxanthin Ocular Supplementation Trial is a randomized single-blind clinical trial that

Table 1. Baseline Demographic, Lifestyle, Anthropometric, and Visual Data

\begin{tabular}{|c|c|c|c|c|c|}
\hline & Entire Group, n (\%) & Group 1, n (\%) & Group 2, n (\%) & Group 3, n (\%) & Significance \\
\hline \multicolumn{6}{|l|}{ Gender } \\
\hline Male & $18(35)$ & $5(29)$ & $8(38)$ & $5(36)$ & \multirow[t]{2}{*}{0.851} \\
\hline Female & $34(65)$ & $12(71)$ & $13(62)$ & $9(64)$ & \\
\hline \multicolumn{6}{|l|}{ Laterality } \\
\hline Right & $33(63)$ & $9(53)$ & $14(67)$ & $10(71)$ & \multirow[t]{2}{*}{0.525} \\
\hline Left & $19(37)$ & $8(47)$ & $7(33)$ & $4(29)$ & \\
\hline \multicolumn{6}{|l|}{ Smoking status } \\
\hline Current & $4(8)$ & $2(12)$ & $2(10)$ & $0(0)$ & \multirow[t]{2}{*}{0.224} \\
\hline Past & $25(48)$ & $8(47)$ & 7 (33) & $10(71)$ & \\
\hline \multirow{2}{*}{\multicolumn{6}{|c|}{ Education }} \\
\hline & & & & & \\
\hline Primary & $10(19)$ & $3(18)$ & $2(10)$ & $5(36)$ & \multirow[t]{3}{*}{0.270} \\
\hline Secondary & $23(44)$ & $6(35)$ & $12(57)$ & \multirow{2}{*}{$\begin{array}{l}5(36) \\
4(28)\end{array}$} & \\
\hline Third level & $19(37)$ & $8(47)$ & $7(33)$ & & \\
\hline Variable & Mean $\pm S D(n=52)$ & Mean $\pm S D(n=17)$ & Mean $\pm S D(n=21)$ & \multicolumn{2}{|c|}{ Mean $\pm S D(n=14)$} \\
\hline Age & $66(8)$ & $65(7)$ & $64(9)$ & $70(8)$ & 0.117 \\
\hline $\mathrm{BMl}, \mathrm{kg} / \mathrm{m}^{2}$ & $26.1(5.5)$ & $25.5(4.1)$ & $27.1(3.6)$ & $25.2(8.6)$ & 0.562 \\
\hline CDVA (study eye) & $99(7)$ & $99(7)$ & $99(8)$ & $98(6)$ & 0.868 \\
\hline \multicolumn{6}{|c|}{ Letter contrast sensitivity } \\
\hline $1.2 \mathrm{cpd}$ & $68.3(46.4)$ & $73.0(49.1)$ & $61.2(41.3)$ & $73.2(52.3)$ & 0.674 \\
\hline $2.4 \mathrm{cpd}$ & 57.1 (41.2) & $59.7(45.3)$ & $56.8(40.5)$ & $54.3(41.4)$ & 0.938 \\
\hline $6.0 \mathrm{cpd}$ & $25.6(14.8)$ & $29.0(14.9)$ & $24.3(14.0)$ & $23.6(16.0)$ & 0.530 \\
\hline $9.6 \mathrm{cpd}$ & $13.7(8.6)$ & $16.0(9.1)$ & $12.3(7.3)$ & $12.9(9.7)$ & 0.399 \\
\hline $15.15 \mathrm{cpd}$ & $6.5(4.9)$ & $7.1(4.5)$ & $6.2(4.8)$ & $6.4(5.7)$ & 0.827 \\
\hline \multicolumn{6}{|c|}{ Macular pigment optical density } \\
\hline $0.25^{\circ}$ eccentricity & $0.50(0.25)$ & $0.50(0.25)$ & $0.50(0.24)$ & $0.47(0.21)$ & 0.925 \\
\hline $0.5^{\circ}$ eccentricity & $0.39(0.22)$ & $0.38(0.27)$ & $0.41(0.22)$ & $0.36(0.19)$ & 0.797 \\
\hline $1.0^{\circ}$ eccentricity & $0.26(0.15)$ & $0.27(0.18)$ & $0.27(0.13)$ & $0.24(0.17)$ & 0.851 \\
\hline $1.75^{\circ}$ eccentricity & $0.14(0.11)$ & $0.16(0.11)$ & $0.15(0.11)$ & $0.11(0.12)$ & 0.554 \\
\hline Diet score ${ }^{*}(n=50) \dagger$ & $18.7(11.2)$ & $17.3(10.9)$ & $21.9(12.7)$ & $16.0(8.4)$ & 0.267 \\
\hline
\end{tabular}

${ }^{*} A$ subject's weekly intake of carotenoid-rich foods was inputted into an L/Z screener to give a carotenoid-based diet score. Values are weighted for frequency of intake of the food and for bioavailability of $L$ and $Z$ within these foods (the range of scores on the $L / Z$ screener is $0-75)$.

†Data were not available for 2 subjects.

$\mathrm{BMI}$, body mass index; CDVA, corrected distance visual acuity; cpd, cycles per degree; SD, standard deviation. 
Table 2. Mean $( \pm S D)$ MPOD at Baseline and 12 Months

\begin{tabular}{|c|c|c|c|c|c|c|c|c|c|}
\hline \multirow[b]{2}{*}{ Eccentricity } & \multicolumn{3}{|c|}{ Group 1} & \multicolumn{3}{|c|}{ Group 2} & \multicolumn{3}{|c|}{ Group 3} \\
\hline & Baseline & 12 Months & $P$ & Baseline & 12 Months & $P$ & Baseline & 12 Months & $P$ \\
\hline $0.25^{\circ}$ & $0.50 \pm 0.25$ & $0.59 \pm 0.30$ & 0.077 & $0.50 \pm 0.25$ & $0.60 \pm 0.21$ & 0.005 & $0.46 \pm 0.21$ & $0.59 \pm 0.20$ & 0.010 \\
\hline $0.5^{\circ}$ & $0.38 \pm 0.27$ & $0.47 \pm 0.27$ & 0.055 & $0.42 \pm 0.22$ & $0.50 \pm 0.19$ & 0.005 & $0.36 \pm 0.19$ & $0.46 \pm 0.21$ & 0.020 \\
\hline $1^{\circ}$ & $0.27 \pm 0.18$ & $0.34 \pm 0.16$ & 0.083 & $0.27 \pm 0.13$ & $0.34 \pm 0.17$ & 0.005 & $0.24 \pm 0.17$ & $0.33 \pm 0.16$ & 0.019 \\
\hline $1.75^{\circ}$ & $0.16 \pm 0.11$ & $0.21 \pm 0.09$ & 0.018 & $0.14 \pm 0.11$ & $0.22 \pm 0.12$ & 0.002 & $0.11 \pm 0.12$ & $0.19 \pm 0.10$ & 0.006 \\
\hline
\end{tabular}

$\mathrm{SD}$, standard deviation.

compares the effect of supplementation with three different macular carotenoid formulations on MPOD, visual performance, and AMD grade, over a period of 12 months, in subjects with early AMD.

The MPOD was significantly greater at 1 year than at baseline at all eccentricities for subjects in Groups 2 and 3. Although the observed augmentation in mean MPOD at 12 months did not reach statistical significance for subjects supplemented with high doses of $\mathrm{L}$ (Group 1) in the absence of MZ, except at $1.75^{\circ}$ eccentricity, it should be noted that the mean increases observed for this group at other eccentricities were not dissimilar in magnitude to those observed for Groups 2 and 3.

The significant rise in MPOD across the spatial profile when all 3 macular carotenoids (Group 2) are included in the formulation, or when supplemented with $17 \mathrm{mg}$ of $\mathrm{MZ}$ and small amounts of $\mathrm{L}$ and $\mathrm{Z}$ (Group 3), and especially the augmentation of MP centrally, is neither surprising nor counter-intuitive, given the known distribution of MP's individual constituent carotenoids. ${ }^{7}$ The inclusion of MZ in the formulation is likely to result in augmentation of MP centrally (demonstrated in Groups 2 and 3 here), as this is the site of dominance of this carotenoid. In addition, the inclusion of $\mathrm{L}$ in the formulation (as in Groups 1, 2, and 3) will result in MP augmentation at the site of that carotenoid's natural dominance $\left(1.75^{\circ}\right)$, attested to by augmentation of MP at this locus in the high L (but no MZ) group (Group 1). It would seem, therefore, that supplementation with all three macular carotenoids results in the greatest augmentation of MPOD across its spatial profile, thereby putatively affording the greatest protection against AMD. Interestingly, in vitro work has concluded that the antioxidant capacity of the macular carotenoids is maximized when all three macular carotenoids are present. ${ }^{42}$

It is unsurprising that there were demonstrable improvements in the CS after augmentation of MP, especially where such augmentation was demonstrated centrally, given the consequential enhancement of prereceptoral filtration of blue light and attenuation of the adverse effects of short-wavelength (blue) light scatter. This is particularly important for subjects with AMD because CS is an important measure of visual function in patients afflicted with the condition. ${ }^{55}$ However, the inclusion of $\mathrm{MZ}$ in the formulation was required to achieve improvements both at low and high spatial frequencies.

The observation in this study that supplementation with high doses of L (in the absence of MZ) resulted in improved CS at low spatial frequencies only is consistent with the fact that visual function at low spatial frequencies will be mediated by slightly eccentric retinal loci. Of note, concentrations of $\mathrm{L}$ are higher in the peripheral macula, compared with the foveola. ${ }^{56}$

Previous studies have investigated the impact of macular carotenoid supplementation on CS in subjects with AMD, with most of the studies reporting improvements in the CS after supplementation (with $\mathrm{L}$ and Z), ${ }^{36,37,57-59}$ although no study to date has tested

Table 3. Mean $( \pm S D)$ Letter CS Values at Baseline and at 12 Months

\begin{tabular}{|c|c|c|c|c|c|c|c|c|c|}
\hline \multirow[b]{2}{*}{$\mathrm{cpd}$} & \multicolumn{3}{|c|}{ Group 1} & \multicolumn{3}{|c|}{ Group 2} & \multicolumn{3}{|c|}{ Group 3} \\
\hline & Baseline & 12 Months & $P$ & Baseline & 12 Months & $P$ & Baseline & 12 Months & $P$ \\
\hline 1.2 & $73.0 \pm 49.1$ & $91.8 \pm 48.5$ & 0.021 & $61.2 \pm 41.3$ & $91.9 \pm 53.6$ & 0.014 & $73.2 \pm 52.3$ & $92.2 \pm 55.0$ & 0.081 \\
\hline 2.4 & $59.7 \pm 45.3$ & $86.7 \pm 54.2$ & 0.006 & $56.8 \pm 40.5$ & $77.8 \pm 51.6$ & 0.008 & $54.3 \pm 41.4$ & $86.2 \pm 52.1$ & 0.002 \\
\hline 6.0 & $29.0 \pm 14.9$ & $38.1 \pm 26.7$ & 0.098 & $24.3 \pm 14.0$ & $30.9 \pm 18.8$ & 0.058 & $23.6 \pm 16.0$ & $42.2 \pm 25.9$ & 0.002 \\
\hline 9.6 & $16.0 \pm 9.1$ & $16.4 \pm 9.0$ & 0.939 & $12.3 \pm 7.3$ & $17.5 \pm 12.3$ & 0.066 & $12.9 \pm 9.7$ & $20.1 \pm 11.9$ & 0.016 \\
\hline 15.15 & $7.1 \pm 4.5$ & $7.8 \pm 5.5$ & 0.408 & $6.2 \pm 4.8$ & $7.8 \pm 6.4$ & 0.189 & $6.4 \pm 5.7$ & $8.7 \pm 5.8$ & 0.005 \\
\hline
\end{tabular}

Note: The statistical tests were based on log-transformed data. The $P$ values reported are for the paired $t$-test (or the corresponding nonparametric test when the data distribution was non-normal).

$\mathrm{cpd}$, cycles per degree; SD, standard deviation. 

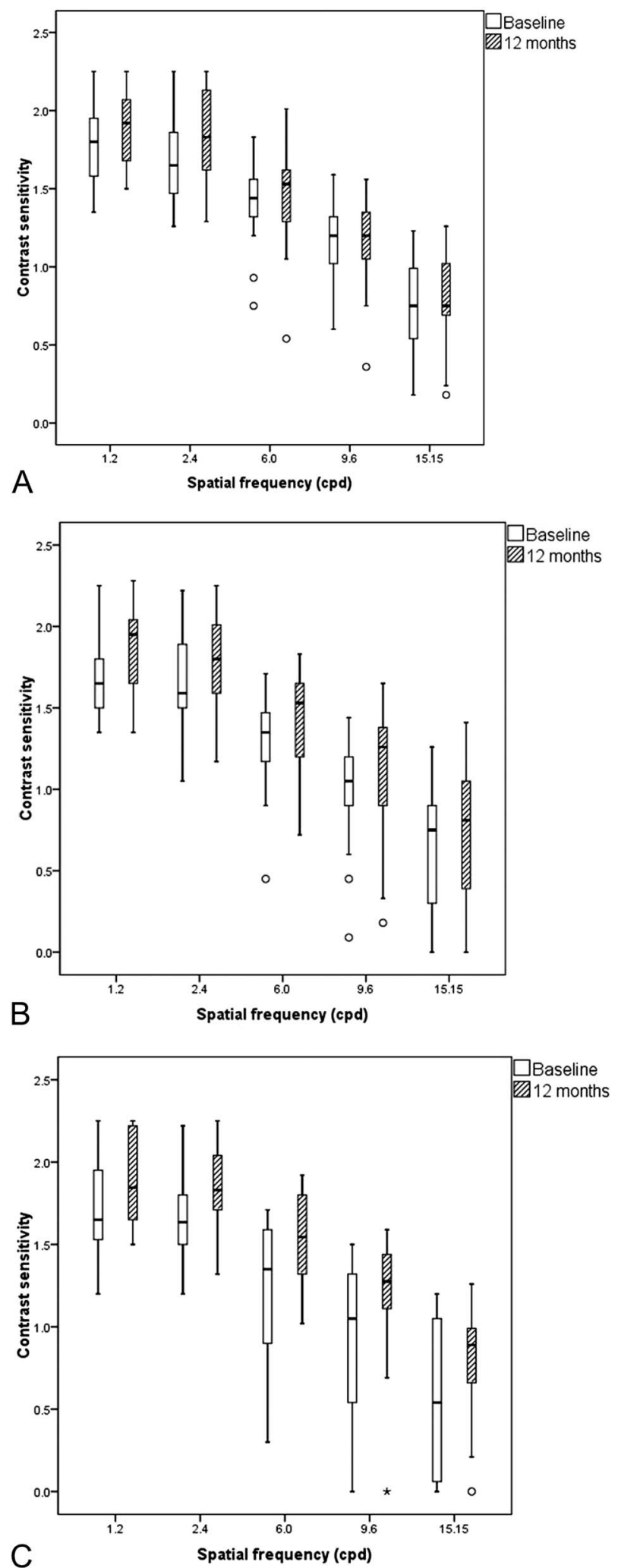

Fig 1. Letter CS at baseline and at 12 months, for Groups 1 (A), 2 (B), AU8 and $3(\mathbf{C})$. a formulation containing MZ. For example, a study by Ma et $\mathrm{al}^{60}$ has shown significant increases in CS at low spatial frequencies after supplementation with either $10 \mathrm{mg} \mathrm{L}, 20 \mathrm{mg} \mathrm{L}$, or $10 \mathrm{mg} \mathrm{L}$ and $10 \mathrm{mg} \mathrm{Z}$ (combined), in subjects with early AMD, over a 48-week study period. These findings are in agreement with those reported in this study, which found demonstrable improvements in CS at high spatial frequencies, but only among subjects who were supplemented with a formulation containing MZ, and not among subjects supplementing with high doses of $\mathrm{L}$ alone.

This study has shown that, from a morphologic perspective, AMD remains stable for at least 12 months after supplementation with the macular carotenoids. However, the findings presented here must be interpreted with full appreciation of the study's principal weaknesses, and these include the small numbers of subjects involved, the study's short duration, and the absence of a placebo group. For the purposes of discussion, it is reasonable to compare our findings with the placebo group in the recently published Carotenoids in Age-Related MAculopathy study, which was a randomized, double-blind, placebo-controlled clinical trial of $\mathrm{L}(12 \mathrm{mg})$ and $\mathrm{Z}$ $(0.6 \mathrm{mg})$ supplementation with co-antioxidants versus placebo in patients with early AMD. ${ }^{61}$ The study population of the Carotenoids in Age-Related MAculopathy study is comparable with that of our study, in inclusion and exclusion criteria, methodology of AMD grading, and demographic and geographic considerations. However, in the Carotenoids in AgeRelated MAculopathy study, at 12 months, $47.4 \%$ of eyes in the placebo arm (108 of 228 eyes) exhibited an increase of least one grade (progression) along the AMD severity scale (data on file). Interestingly, in this study, only $27 \%$ of subjects (all of whom were supplementing with the macular carotenoids) showed progression by one or more steps at 12 months. Of course, a historical comparison such as this one should be interpreted with full appreciation of the fact that the natural course of AMD, particularly over a 12-month period, may not be clinically significant.

No discussion of our findings would be complete without reference to the recently published AREDS2 reports, ${ }^{62,63}$ where analysis of secondary outcomes indicated a benefit of supplementation with $\mathrm{L}$ and Z, in terms of AMD progression and preservation of vision, especially in subjects with low dietary intake of those two carotenoids. Given that only two of the three macular carotenoids were used in AREDS2, our findings are rendered all the more clinically meaningful, if not somewhat provocative.

Of note, AREDS, published in $2001,{ }^{64}$ was criticized for non-inclusion of $\mathrm{L}$ and $\mathrm{Z}$, and that omission 
Table 4. Clinical Pathology Variables Following Supplementation With the Macular Carotenoids Assessed at Baseline and at 12 months for Each of the Three Intervention Groups

\begin{tabular}{|c|c|c|c|c|c|}
\hline \multirow[b]{2}{*}{ Pathology Variable } & \multirow[b]{2}{*}{ Function of Test } & \multirow[b]{2}{*}{ Reference Range (Unit) ${ }^{\star}$} & \multicolumn{2}{|c|}{ Group $1(n=9) \dagger$} & \multirow[b]{2}{*}{$P$} \\
\hline & & & Baseline & 12 Months & \\
\hline Sodium & Renal profile & 135-145 (mmol/L) & $139 \pm 3$ & $138 \pm 3$ & 0.312 \\
\hline Potassium & Renal profile & $3.3-5.3(\mathrm{mmol} / \mathrm{L})$ & $4.6 \pm 0.3$ & $4.7 \pm 0.2$ & 0.366 \\
\hline Chloride & Renal profile & 98-107 (mmol/L) & $104 \pm 2$ & $106 \pm 2$ & 0.073 \\
\hline Urea & Renal profile & $2.5-7.7$ (mmol/L) & $7.2 \pm 2.4$ & $6.5 \pm 1.4$ & 0.174 \\
\hline Creatinine & Renal profile & 40-90 ( $\mu \mathrm{mol} / \mathrm{L})$ & $81 \pm 13$ & $74 \pm 10$ & 0.086 \\
\hline Total protein & Liver profile & $64-83(\mathrm{~g} / \mathrm{L})$ & $69 \pm 3$ & $68 \pm 3$ & 0.499 \\
\hline Albumin & Liver profile & $37-52$ (g/L) & $41 \pm 2$ & $40 \pm 3$ & 0.444 \\
\hline Globulins & Liver profile & $21-36(\mathrm{~g} / \mathrm{L})$ & $28 \pm 4$ & $28 \pm 3$ & 1.000 \\
\hline Total bilirubin & Liver profile & 3.4-21.0 ( $\mu \mathrm{mol} / \mathrm{L})$ & $6.2 \pm 2.0$ & $7.8 \pm 2.2$ & 0.050 \\
\hline AAT & Liver profile & $0-55 \mathrm{IU} / \mathrm{L}$ & $23 \pm 8$ & $21 \pm 8$ & 0.426 \\
\hline ASA & Liver profile & 5-36 IU/L & $24 \pm 3$ & $24 \pm 4$ & 0.782 \\
\hline Alkaline phosphate & Liver profile & 40-150 IU/L & $79 \pm 27$ & $87 \pm 31$ & 0.013 \\
\hline GGT & Liver profile & 9-36 IU/L & $39 \pm 40$ & $40 \pm 41$ & 0.668 \\
\hline Cholesterol total & Lipid profile & $<5.0(\mathrm{mmol} / \mathrm{L})$ & $5.2 \pm 1.0$ & $5.2 \pm 1.1$ & 0.708 \\
\hline Triglycerides & Lipid profile & $0.60-1.70(\mathrm{mmol} / \mathrm{L})$ & $1.47 \pm 0.61$ & $1.34 \pm 0.66$ & 0.185 \\
\hline HDL & Lipid profile & $1.00-1.55(\mathrm{mmol} / \mathrm{L})$ & $1.51 \pm 0.37$ & $1.43 \pm 0.31$ & 0.063 \\
\hline Direct LDL & Lipid profile & $<3.0(\mathrm{mmol} / \mathrm{L})$ & $3.1 \pm 1.0$ & $3.2 \pm 1.0$ & 0.419 \\
\hline Calcium & Bone profile & $2.10-2.60(\mathrm{mmol} / \mathrm{L})$ & $2.31 \pm 0.10$ & $2.32 \pm 0.14$ & 0.661 \\
\hline Phosphate & Bone profile & $0.80-1.56(\mathrm{mmol} / \mathrm{L})$ & $1.13 \pm 0.17$ & $1.20 \pm 0.24$ & 0.292 \\
\hline Magnesium & Bone profile & $0.65-1.10(\mathrm{mmol} / \mathrm{L})$ & $0.99 \pm 0.05$ & $0.94 \pm 0.09$ & 0.159 \\
\hline Uric Acid & Bone profile & 155-394 ( $\mu \mathrm{mol} / \mathrm{L})$ & $290 \pm 54$ & $280 \pm 62$ & 0.579 \\
\hline Glucose & Bone profile & $3.1-6.1$ (mmol/L) & $5.3 \pm 0.7$ & $5.3 \pm 1.2$ & 0.910 \\
\hline HSRP & $\begin{array}{l}\text { Inflammation } \\
\text { marker }\end{array}$ & $<5.0(\mathrm{mg} / \mathrm{L})$ & $1.2 \pm 0.5$ & $1.6 \pm 1.0$ & 0.097 \\
\hline \multicolumn{6}{|l|}{ Full blood count } \\
\hline Leukocyte count & Hematology & 3.88-10.49 (10e9/L) & $6.54 \pm 2.00$ & $5.88 \pm 1.03$ & 0.331 \\
\hline Erythrocyte count & Hematology & 3.73-5.02 (10e12/L) & $4.51 \pm 0.42$ & $4.36 \pm 0.33$ & 0.367 \\
\hline Hemoglobin & Hematology & $11.3-15.2(\mathrm{~g} / \mathrm{dL})$ & $13.6 \pm 1.1$ & $13.6 \pm 0.9$ & 0.622 \\
\hline Hematocrit & Hematology & $0.323-0.462$ (L/L) & $0.407 \pm 0.032$ & $0.405 \pm 0.020$ & 0.769 \\
\hline MCV & Hematology & $83.1-99.1(\mathrm{fL})$ & $90.5 \pm 3.1$ & $93.1 \pm 5.1$ & 0.222 \\
\hline $\mathrm{MCH}$ & Hematology & 28.3-33.9 (pg) & $30.1 \pm 1.2$ & $31.3 \pm 1.8$ & 0.134 \\
\hline $\mathrm{MCHC}$ & Hematology & $32.1-36.6$ (g/dL) & $33.3 \pm 1.0$ & $33.6 \pm 0.8$ & 0.357 \\
\hline Platelets & Hematology & 164-382 (10e9/L) & $332 \pm 249$ & $249 \pm 123$ & 0.196 \\
\hline \multicolumn{6}{|l|}{ Differential white cell count } \\
\hline Neutrophils & Hematology & 1.91-7.16 (10e9/L) & $3.80 \pm 1.27$ & $3.44 \pm 0.82$ & 0.423 \\
\hline Lymphocytes & Hematology & $1.01-3.13(10 \mathrm{e} 9 / \mathrm{L})$ & $1.82 \pm 0.54$ & $1.66 \pm 0.39$ & 0.309 \\
\hline Monocytes & Hematology & $0.19-0.68$ (10e9/L) & $0.47 \pm 0.18$ & $0.40 \pm 0.13$ & 0.322 \\
\hline Eosinophils & Hematology & $0.05-0.51$ (10e9/L) & $0.22 \pm 0.05$ & $0.18 \pm 0.06$ & 0.195 \\
\hline Basophils & Hematology & $0.02-0.15$ (10e9/L) & $0.05 \pm 0.03$ & $0.05 \pm 0.02$ & 0.505 \\
\hline Large unstained cells & Hematology & $0.00-0.30$ (10e9/L) & $0.17 \pm 0.07$ & $0.14 \pm 0.03$ & 0.222 \\
\hline
\end{tabular}

\begin{tabular}{|c|c|c|c|c|c|c|}
\hline \multirow[b]{2}{*}{ Pathology Variable } & \multicolumn{2}{|c|}{ Group $2(n=20) \dagger$} & \multirow[b]{2}{*}{$P$} & \multicolumn{2}{|c|}{ Group $3(n=12) \dagger$} & \multirow[b]{2}{*}{$P$} \\
\hline & Baseline & 12 Months & & Baseline & 12 Months & \\
\hline Sodium & $141 \pm 3$ & $138 \pm 2$ & 0.001 & $136 \pm 3$ & $137 \pm 4$ & 0.371 \\
\hline Potassium & $4.6 \pm 0.4$ & $4.7 \pm 0.4$ & 0.475 & $4.7 \pm 0.3$ & $4.8 \pm 0.2$ & 0.709 \\
\hline Chloride & $104 \pm 3$ & $104 \pm 3$ & 0.922 & $103 \pm 4$ & $103 \pm 4$ & 0.612 \\
\hline Urea & $6.1 \pm 1.1$ & $6.6 \pm 1.5$ & 0.073 & $6.7 \pm 1.5$ & $6.0 \pm 1.7$ & 0.053 \\
\hline Creatinine & $78 \pm 14$ & $77 \pm 15$ & 0.299 & $76 \pm 19$ & $75 \pm 17$ & 0.681 \\
\hline Total protein & $71 \pm 4$ & $70 \pm 3$ & 0.415 & $70 \pm 5$ & $70 \pm 5$ & 0.558 \\
\hline Albumin & $43 \pm 2$ & $42 \pm 2$ & 0.134 & $41 \pm 2$ & $42 \pm 2$ & 0.410 \\
\hline Globulins & $28 \pm 4$ & $29 \pm 3$ & 0.737 & $29 \pm 5$ & $28 \pm 4$ & 0.272 \\
\hline Total bilirubin & $9.1 \pm 4.7$ & $9.9 \pm 5.3$ & 0.293 & $8.0 \pm 3.6$ & $10.1 \pm 4.0$ & 0.001 \\
\hline AAT & $22 \pm 6$ & $22 \pm 6$ & 0.752 & $19 \pm 3$ & $20 \pm 5$ & 0.279 \\
\hline ASA & $22 \pm 4$ & $22 \pm 4$ & 0.903 & $21 \pm 3$ & $22 \pm 4$ & 0.083 \\
\hline Alkaline phosphate & $78 \pm 20$ & $79 \pm 20$ & 0.501 & $76 \pm 11$ & $82 \pm 17$ & 0.114 \\
\hline GGT & $27 \pm 11$ & $28 \pm 14$ & 0.395 & $27 \pm 16$ & $32 \pm 23$ & 0.075 \\
\hline
\end{tabular}


Table 4. (Continued)

\begin{tabular}{|c|c|c|c|c|c|c|}
\hline \multirow[b]{2}{*}{ Pathology Variable } & \multicolumn{2}{|c|}{ Group $2(n=20) \dagger$} & \multirow[b]{2}{*}{$P$} & \multicolumn{2}{|c|}{ Group $3(n=12) \dagger$} & \multirow[b]{2}{*}{$P$} \\
\hline & Baseline & 12 Months & & Baseline & 12 Months & \\
\hline Cholesterol total & $4.7 \pm 1.3$ & $4.5 \pm 0.9$ & 0.231 & $4.8 \pm 1.0$ & $4.8 \pm 0.9$ & 1.000 \\
\hline Triglycerides & $1.44 \pm 0.49$ & $1.39 \pm 0.60$ & 0.700 & $1.51 \pm 1.31$ & $1.29 \pm 0.82$ & 0.236 \\
\hline $\mathrm{HDL}$ & $1.31 \pm 0.33$ & $1.24 \pm 0.28$ & 0.044 & $1.46 \pm 0.47$ & $1.46 \pm 0.51$ & 0.942 \\
\hline Direct LDL & $2.8 \pm 1.1$ & $2.7 \pm 0.8$ & 0.317 & $2.8 \pm 0.9$ & $2.7 \pm 0.9$ & 0.671 \\
\hline Calcium & $2.35 \pm 0.07$ & $2.35 \pm 0.07$ & 0.825 & $2.31 \pm 0.06$ & $2.40 \pm 0.11$ & 0.005 \\
\hline Phosphate & $1.17 \pm 0.17$ & $1.19 \pm 0.19$ & 0.672 & $1.07 \pm 0.25$ & $1.10 \pm 0.21$ & 0.414 \\
\hline Magnesium & $0.97 \pm 0.08$ & $0.98 \pm 0.06$ & 0.573 & $0.93 \pm 0.12$ & $0.94 \pm 0.08$ & 0.599 \\
\hline Uric Acid & $315 \pm 65$ & $312 \pm 66$ & 0.724 & $305 \pm 65$ & $322 \pm 89$ & 0.260 \\
\hline Glucose & $5.0 \pm 0.6$ & $5.0 \pm 0.7$ & 0.867 & $5.0 \pm 0.9$ & $5.1 \pm 0.7$ & 0.273 \\
\hline HSRP & $2.2 \pm 2.4$ & $2.3 \pm 2.1$ & 0.864 & $4.0 \pm 5.1$ & $4.3 \pm 6.7$ & 0.728 \\
\hline \multicolumn{7}{|l|}{ Full blood count } \\
\hline Leukocyte count & $6.74 \pm 1.53$ & $6.81 \pm 1.78$ & 0.830 & $6.13 \pm 1.56$ & $5.95 \pm 1.10$ & 0.661 \\
\hline Erythrocyte count & $4.50 \pm 0.41$ & $4.47 \pm 0.39$ & 0.377 & $4.44 \pm 0.45$ & $4.46 \pm 0.45$ & 0.858 \\
\hline Hemoglobin & $13.7 \pm 1.1$ & $13.7 \pm 1.2$ & 0.596 & $13.6 \pm 1.2$ & $13.6 \pm 1.1$ & 0.969 \\
\hline Hematocrit & $0.413 \pm 0.031$ & $0.413 \pm 0.031$ & 0.939 & $0.409 \pm 0.031$ & $0.412 \pm 0.031$ & 0.779 \\
\hline MCV & $92.0 \pm 4.0$ & $92.6 \pm 4.0$ & 0.414 & $92.4 \pm 3.7$ & $92.6 \pm 3.7$ & 0.778 \\
\hline $\mathrm{MCH}$ & $30.4 \pm 1.3$ & $30.8 \pm 1.2$ & 0.167 & $30.7 \pm 1.2$ & $30.5 \pm 1.4$ & 0.632 \\
\hline $\mathrm{MCHC}$ & $33.1 \pm 0.8$ & $33.3 \pm 1.2$ & 0.523 & $33.2 \pm 1.1$ & $33.0 \pm 1.0$ & 0.468 \\
\hline Platelets & $258 \pm 88$ & $250 \pm 118$ & 0.527 & $244 \pm 46$ & $254 \pm 61$ & 0.369 \\
\hline Neutrophils & $4.09 \pm 1.20$ & $4.23 \pm 1.38$ & 0.580 & $3.92 \pm 1.23$ & $3.84 \pm 1.21$ & 0.809 \\
\hline Lymphocytes & $1.81 \pm 0.43$ & $1.70 \pm 0.42$ & 0.128 & $1.42 \pm 0.36$ & $1.38 \pm 0.39$ & 0.704 \\
\hline Monocytes & $0.43 \pm 0.11$ & $0.45 \pm 0.16$ & 0.495 & $0.41 \pm 0.12$ & $0.35 \pm 0.09$ & 0.132 \\
\hline Eosinophils & $0.18 \pm 0.09$ & $0.23 \pm 0.13$ & 0.055 & $0.17 \pm 0.10$ & $0.17 \pm 0.08$ & 1.000 \\
\hline Basophils & $0.05 \pm 0.02$ & $0.07 \pm 0.04$ & 0.063 & $0.04 \pm 0.02$ & $0.06 \pm 0.03$ & 0.042 \\
\hline Large unstained cells & $0.18 \pm 0.07$ & $0.16 \pm 0.05$ & 0.122 & $0.16 \pm 0.05$ & $0.14 \pm 0.02$ & 0.177 \\
\hline
\end{tabular}

${ }^{*}$ The normative reference ranges for this study were obtained from the insert kits for the instrumentation used by Biomnis Laboratories. Exceptions were the reference ranges for lipids (HDL, LDL, total cholesterol, and triglycerides), which were obtained from the European AU10 Guidelines on Cardiovascular Disease Prevention, (69) and for glucose, which were obtained from the World Health Organization (70).

AU11 TTotal $n \neq 52$ because data on pathology analysis was not available for all subjects at both baseline and 12 months.

AAT, alanine aminotransferase; ASA, aspartate aminotransferase; GGT, gamma glutamyl transpeptidase; HDL, high-density lipoprotein; LDL, low-density lipoprotein; HSCP, high sensitive reactive protein; $\mathrm{MCH}$, mean corpuscular hemoglobin; MCHC, mean corpuscular hemoglobin concentration; MCV, mean corpuscular volume.

prompted AREDS2. Our findings, however, suggest that the exclusion of MZ in AREDS2 represents a potential shortcoming of that study, especially given that MP was measured in less than $2 \%$ of AREDS2 patients. Certainly, the opportunity to demonstrate further visual benefit by inclusion of all three of MP's constituent carotenoids was missed, and warrants further study. In this vein, a head-to-head randomized, double-blind, controlled trial of the AREDS2 formula versus the AREDS2 formula fortified with MZ is currently underway. ${ }^{65}$

\section{Conclusion}

Macular pigment can be augmented, and CS enhanced, in subjects with early AMD who receive supplemental macular carotenoids. A formulation containing all three macular carotenoids $(\mathrm{L}, \mathrm{Z}$, and MZ) may offer advantages over a formulation that does not contain MZ, in terms of improvements in CS and MP augmentation across its spatial profile, the latter putatively affording greater protection against (photo-) oxidative injury. The results of this study

Table 5. Change in AMD Grade (11-Step Scale) Between Baseline and 12 Months

\begin{tabular}{llllllllr}
\hline Group & $\mathrm{n}$ & $-2(\%)$ & $-1(\%)$ & $0(\%)$ & $+1(\%)$ & $+2(\%)$ & $+3(\%)$ & Significance \\
\hline 1 & 17 & $1(5.9)$ & $1(5.9)$ & $10(58.8)$ & $3(17.6)$ & $1(5.9)$ & $1(5.9)$ & 0.455 \\
2 & 21 & $3(14.3)$ & $2(9.5)$ & $11(52.4)$ & $3(14.3)$ & $2(9.5)$ & 0 & 0 \\
3 & 14 & $2(14.3)$ & $5(35.7)$ & $4(28.6)$ & $2(14.3)$ & $1(7.1)$ & $1(1.9)$ & \\
Total & $52(100 \%)$ & $6(11.5)$ & $8(15.4)$ & $25(48.1)$ & $8(15.4)$ & $4(7.7)$ & $1(1)$ \\
\hline
\end{tabular}

Negative value, disease progression; positive value, disease regression; 0 , no change in grade. 
should inform and prompt a well-designed, controlled clinical trial of supplementation with $\mathrm{L}, \mathrm{Z}$, and $\mathrm{MZ}$ in subjects with AMD, where outcome measures should include visual function and disease progression.

Key words: lutein, zeaxanthin, meso-zeaxanthin, age-related macular degeneration, visual performance.

\section{References}

1. Bressler NM. Age-related macular degeneration is the leading cause of blindness. JAMA 2004;291:1900-1901.

2. Kelliher C, Kenny D, O'Brien C. Trends in blind registration in the adult population of the Republic of Ireland 1996-2003. Br J Ophthalmol 2006;90:367-371.

3. Owen CG, Jarrar Z, Wormald R, et al. The estimated prevalence and incidence of late stage age related macular degeneration in the UK. Br J Ophthalmol 2012;96:752-756.

4. Rosenfeld PJ, Rich RM, Lalwani GA. Ranibizumab: phase III clinical trial results. Ophthalmol Clin North Am 2006;19: 361-372.

5. Trieschmann M, van Kuijk FJ, Alexander R, et al. Macular pigment in the human retina: histological evaluation of localization and distribution. Eye (Lond) 2008;22:132-137.

6. Hammond BR, Wooten BR, Snodderly DM. Individual variations in the spatial profile of human macular pigment. J Opt Soc Am A Opt Image Sci Vis 1997;14:1187-1196.

7. Bone RA, Landrum JT, Hime GW, et al. Stereochemistry of the human macular carotenoids. Invest Ophthalmol Vis Sci 1993;34:2033-2040.

8. Snodderly DM, Brown PK, Delori FC, Auran JD. The macular pigment. I. Absorbance spectra, localization, and discrimination from other yellow pigments in primate retinas. Invest Ophthalmol Vis Sci 1984;25:660-673.

9. Tomany SC, Cruickshanks KJ, Klein R, et al. Sunlight and the 10-year incidence of age-related maculopathy: the Beaver Dam Eye study. Arch Ophthalmol 2004;122:750-757.

10. Beatty S, Koh H, Phil M, et al. The role of oxidative stress in the pathogenesis of age-related macular degeneration. Surv Ophthalmol 2000;45:115-134.

11. Nolan JM, Stack J, O’Donovan O, Loane E, Beatty S. Risk factors for age-related maculopathy are associated with a relative lack of macular pigment. Exp Eye Res 2007;84:61-74.

12. Seddon JM, Ajani UA, Sperduto RD, et al. Dietary carotenoids, vitamins A, C, and E, and advanced age-related macular degeneration. Eye Disease Case-Control Study Group. JAMA 1994;272:1413-1420.

13. Mares-Perlman JA, Fisher AI, Klein R, et al. Lutein and zeaxanthin in the diet and serum and their relation to age-related maculopathy in the third national health and nutrition examination survey. Am J Epidemiol 2001;153:424-432.

14. Snellen ELM, Verbeek ALM, Van Den Hoogen GWP, et al. Neovascular age-related macular degeneration and its relationship to antioxidant intake. Acta Ophthalmol Scand 2002;80: 368-371.

15. San Giovanni JP, Chew EY, Clemons TE, et al, AREDS Research Group. Dietary lipid intake and incident advanced age-related macular degeneration (AMD) in the Age-Related Eye Disease Study (AREDS). Invest Ophthalmol Vis Sci 2005; 46:2382.

16. Tan JS, Wang JJ, Flood V, et al. Dietary antioxidants and the long-term incidence of age-related macular degeneration the
17. Antioxidant status and neovascular age-related macular degeneration. Eye Disease Case-Control Study Group. Arch Ophthalmol 1993;111:104-109.

18. Delcourt C, Carriere I, Delage M, et al. Plasma lutein and zeaxanthin and other carotenoids as modifiable risk factors for age-related maculopathy and cataract: the POLA Study. Invest Ophthalmol Vis Sci 2006;47:2329-2335.

19. Fletcher AE, Bentham GC, Agnew M, et al. Sunlight exposure, antioxidants, and age-related macular degeneration. Arch Ophthalmol 2008;126:1396-1403.

20. Hammond BR, Johnson EJ, Russell RM, et al. Dietary modification of human macular pigment density. Invest Ophthalmol Vis Sci 1997;38:1795-1801.

21. Johnson EJ, Hammond BR, Yeum KJ, et al. Relation among serum and tissue concentrations of lutein and zeaxanthin and macular pigment density. Am J Clin Nutr 2000;71:1555-1562.

22. Bone RA, Landrum JT, Guerra LH, et al. Lutein and zeaxanthin dietary supplements raise macular pigment density and serum concentrations of these carotenoids in humans. J Nutr 2003;133:992-998.

23. Trieschmann M, Beatty S, Nolan JM, et al. Changes in macular pigment optical density and serum concentrations of its constituent carotenoids following supplemental lutein and zeaxanthin: the LUNA study. Exp Eye Res 2007;84:718-728.

24. Schalch W, Cohn W, Barker FM, et al. Xanthophyll accumulation in the human retina during supplementation with lutein or zeaxanthin-the LUXEA (LUtein Xanthophyll Eye Accumulation) study. Arch Biochem Biophys 2007;458:128-135.

25. Richer S, Devenport J, Lang JC. LAST II: differential temporal responses of macular pigment optical density in patients with atrophic age-related macular degeneration to dietary supplementation with xanthophylls. Optometry 2007;78:213-219.

26. Nolan JM, Loughman J, Akkali MC, et al. The impact of macular pigment augmentation on visual performance in normal subjects: COMPASS. Vision Res 2011.

27. Sommerburg O, Keunen JE, Bird AC, van Kuijk FJ. Fruits and vegetables that are sources for lutein and zeaxanthin: the macular pigment in human eyes. Br J Ophthalmol 1998;82: 907-910.

28. Perry A, Rasmussen H, Johnson EJ. Xanthophyll (lutein, zeaxanthin) content in fruits, vegetables and corn and egg products. J Food Compost Anal 2009;22:9-15.

29. Maoka T, Arai A, Shimizu M, Matsuno T. The first isolation of enantiomeric and meso-zeaxanthin in nature. Comp Biochem Physiol B 1986;83:121-124.

30. Connolly EE, Beatty S, Thurnham DI, et al. Augmentation of macular pigment following supplementation with all three macular carotenoids: an exploratory study. Curr Eye Res 2010;35:335-351.

31. Loughman J, Akkali MC, Beatty S, et al. The relationship between macular pigment and visual performance. Vision Res 2010;50:1249-1256.

32. Engles M, Wooten B, Hammond B. Macular pigment: a test of the acuity hypothesis. Invest Ophthalmol Vis Sci 2007;48: 2922-2931.

33. Kvansakul J, Rodriguez-Carmona M, Edgar DF, et al. Supplementation with the carotenoids lutein or zeaxanthin improves human visual performance. Ophthalmic Physiol Opt 2006;26: 362-371.

34. Stringham JM, Hammond BR Jr. The glare hypothesis of macular pigment function. Optom Vis Sci 2007;84:859-864.

35. Wooten BR, Hammond BR. Macular pigment: influences on visual acuity and visibility. Prog Retin Eye Res 2002;21: 225-240. 
36. Richer S, Stiles W, Statkute L, et al. Double-masked, placebocontrolled, randomized trial of lutein and antioxidant supplementation in the intervention of atrophic age-related macular degeneration: the Veterans LAST study (Lutein Antioxidant Supplementation Trial). Optometry 2004;75:216-230.

37. Richer SP, Stiles W, Graham-Hoffman K, et al. Randomized, double-blind, placebo-controlled study of zeaxanthin and visual function in patients with atrophic age-related macular degeneration: the Zeaxanthin and Visual Function Study (ZVF) FDA IND \#78, 973. Optometry 2011;82:667-680.

38. Beatty S, Chakravarthy U, Nolan JM, et al. Secondary outcomes in a clinical trial of carotenoids with coantioxidants versus placebo in early age-related macular degeneration. Ophthalmology 2013;120:600-606.

39. Johnson EJ, Neuringer M, Russell RM, et al. Nutritional manipulation of primate retinas, III: effects of lutein or zeaxanthin supplementation on adipose tissue and retina of xanthophyll-free monkeys. Invest Ophthalmol Vis Sci 2005; 46:692-702.

40. Bone RA, Landrum JT, Friedes LM, et al. Distribution of lutein and zeaxanthin stereoisomers in the human retina. Exp Eye Res 1997;64:211-218.

41. Bhosale P, Bernstein PS. Synergistic effects of zeaxanthin and its binding protein in the prevention of lipid membrane oxidation. Biochim Biophys Acta 2005;1740:116-121.

42. Li B, Ahmed F, Bernstein PS. Studies on the singlet oxygen scavenging mechanism of human macular pigment. Arch Biochem Biophys 2010.

43. Landrum JT, Bone RA. Lutein, zeaxanthin, and the macular pigment. Arch Biochem Biophys 2001;385:28-40.

44. Billsten HH, Bhosale P, Yemelyanov A, et al. Photophysical properties of xanthophylls in carotenoproteins from human retinas. Photochem Photobiol 2003;78:138-145.

45. Kirby ML, Beatty S, Loane E, et al. A central dip in the macular pigment spatial profile is associated with age and smoking. Invest Ophthalmol Vis Sci 2010;51:6722-6728.

46. Nolan JM, Akkali MC, Loughman J, et al. Macular carotenoid supplementation in subjects with atypical spatial profiles of macular pigment. Exp Eye Res 2012;101:9-15.

47. Wooten BR, Hammond BR, Land RI, Snodderly DM. A practical method for measuring macular pigment optical density. Invest Ophthalmol Vis Sci 1999;40:2481-2489.

48. Loane E, Stack J, Beatty S, Nolan JM. Measurement of macular pigment optical density using two different heterochromatic flicker photometers. Curr Eye Res 2007;32:555-564.

49. Stringham JM, Hammond BR. Macular pigment and visual performance under glare conditions. Optom Vis Sci 2008;85: $82-88$.

50. Klein R, Davis MD, Magli YL, et al. The Wisconsin agerelated maculopathy grading system. Ophthalmology 1991; 98:1128-1134.
51. Sparrow JM, Dickinson AJ, Duke AM. The Wisconsin agerelated macular degeneration grading system: performance in an independent centre. Ophthalmic Epidemiol 1997;4:49-55.

52. Klein R, Klein BE, Knudtson MD, et al. Fifteen-year cumulative incidence of age-related macular degeneration: the Beaver Dam Eye Study. Ophthalmology 2007;114:253-262.

53. Connolly EE, Beatty S, Loughman J, et al. Supplementation with all three macular carotenoids: response, stability, and safety. Invest Ophthalmol Vis Sci 2011;52:9207-9217.

54. Cohen J. Statistical Power Analysis for the Behavioral Sciences. 2nd ed. Hillsdale, New Jersey: Lawrence Erlbaum Associates; 1988.

55. Stangos N, Voutas S, Topouzis F, Karampatakis V. Contrast sensitivity evaluation in eyes predisposed to age-related macular degeneration and presenting normal visual acuity. Ophthalmologica 1995;209:194-198.

56. Landrum JT, Bone RA, Moore LL, Gomez CM. Analysis of zeaxanthin distribution within individual human retinas. Methods Enzymol 1999;299:457-467.

57. Piermarocchi S, Saviano S, Parisi V, et al. Carotenoids in Agerelated Maculopathy Italian Study (CARMIS): two-year results of a randomized study. Eur J Ophthalmol 2011;22:216-225.

58. Sasamoto Y, Gomi F, Sawa M, et al. Effect of 1-year lutein supplementation on macular pigment optical density and visual function. Graefes Arch Clin Exp Ophthalmol 2011; 249:1847-1854.

59. Bartlett HE, Eperjesi F. Effect of lutein and antioxidant dietary supplementation on contrast sensitivity in age-related macular disease: a randomized controlled trial. Eur J Clin Nutr 2007;61: 1121-1127.

60. Ma L, Yan SF, Huang YM, et al. Effect of lutein and zeaxanthin on macular pigment and visual function in patients with early age-related macular degeneration. Ophthalmology 2012.

61. Neelam K, Hogg RE, Stevenson MR, et al. Carotenoids and co-antioxidants in age-related maculopathy: design and methods. Ophthalmic Epidemiol 2008;15:389-401.

62. Chew EY, SanGiovanni JP, Ferris FL, et al. Lutein/zeaxanthin for the treatment of age-related cataract: AREDS2 randomized trial report no. 4. JAMA Ophthalmol 2013;131:843-850.

63. Chew EY, Clemons TE, SanGiovanni JP, et al. Secondary analyses of the effects of lutein/zeaxanthin on age-related macular degeneration progression: AREDS2 report no. 3. JAMA Ophthalmol 2013.

64. Kassoff A, Kassoff J, Buehler J, et al. A randomized, placebocontrolled, clinical trial of high-dose supplementation with vitamins $\mathrm{C}$ and $\mathrm{E}$, beta carotene, and zinc for age-related macular degeneration and vision loss-AREDS report no. 8. Arch Ophthalmol 2001;119:1417-1436.

65. Akuffo KO, Beatty S, Stack J, et al. Central retinal enrichment supplementation trials: design and methodology. Ophthalmic Epidemiol 2013. In press. 